\title{
Hampton Roads Regional Water-Quality Monitoring Program
}

How much nitrogen, phosphorus, and suspended solids are contributed by the highly urbanized areas of the Hampton Roads region in Virginia to Chesapeake Bay? The answer to this complex question has major implications for policy decisions, resource allocations, and efforts aimed at restoring clean waters to Chesapeake Bay and its tributaries. To quantify the amount of nitrogen, phosphorus, and suspended solids delivered to the bay from this region, the U.S. Geological Survey (USGS) has partnered with the Hampton Roads Sanitation District (HRSD), in cooperation with the Hampton Roads Planning District Commission (HRPDC), to conduct a water-quality monitoring program throughout the Hampton Roads region.

\section{Why a Regional Water-Quality Program in Hampton Roads?}

The Atlantic Coastal Plain, in which the Hampton Roads region of Virginia is located, is defined by low elevation and topographic relief, which when combined with urban development result in a unique ecological and hydrological environment. In recent years, quantification of, and regulations pertaining to, suspended solids and nutrient contributions to Chesapeake Bay have been based on monitoring conducted in areas largely outside the Coastal Plain Physiographic Province. It is unknown, however, whether the results of these monitoring programs represent the predominantly urban Hampton Roads region of the Coastal Plain.

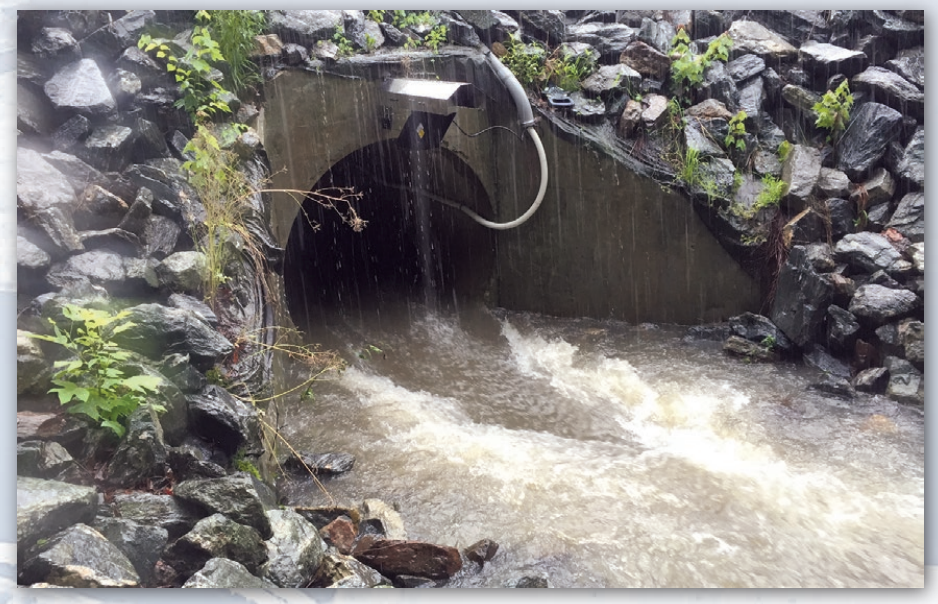

A water-quality sonde and flow meter measure storm conditions at a conveyance outfall in Newport News, Va.

\section{How Does Urban Stormwater Affect the Health of Chesapeake Bay?}

The region's flat topographic relief results in meandering rivers and streams that ultimately flow into tidal estuaries. Undisturbed, these environments can act as buffers between uplands and receiving waters, such as Chesapeake Bay. Theoretically, the slow moving waters do not have the energy required to transport large quantities of suspended solids, such as sediment, and could provide ample residence time for organisms to consume nutrients, such as nitrogen and phosphorus, that may be washed in by upland runoff.
Urbanization in the region has led to increased imperviousness (roads, sidewalks, parking lots, rooftops) and compacted soils that prevent rainwater from infiltrating into the ground. Because of urbanization, rainfall rapidly collects on the land surface and runs off into receiving waters, potentially creating the energy needed to mobilize greater amounts of particulate materials and reducing the residence time available for ecological removal of nutrients. During storms, the rapid accumulation of rainfall on impervious land surfaces, combined with the regions flat topography, produces the potential for flooding. To manage runoff from impervious areas, the region is underlain with an extensive network of storm sewers designed to collect and export stormwater runoff. Although these systems

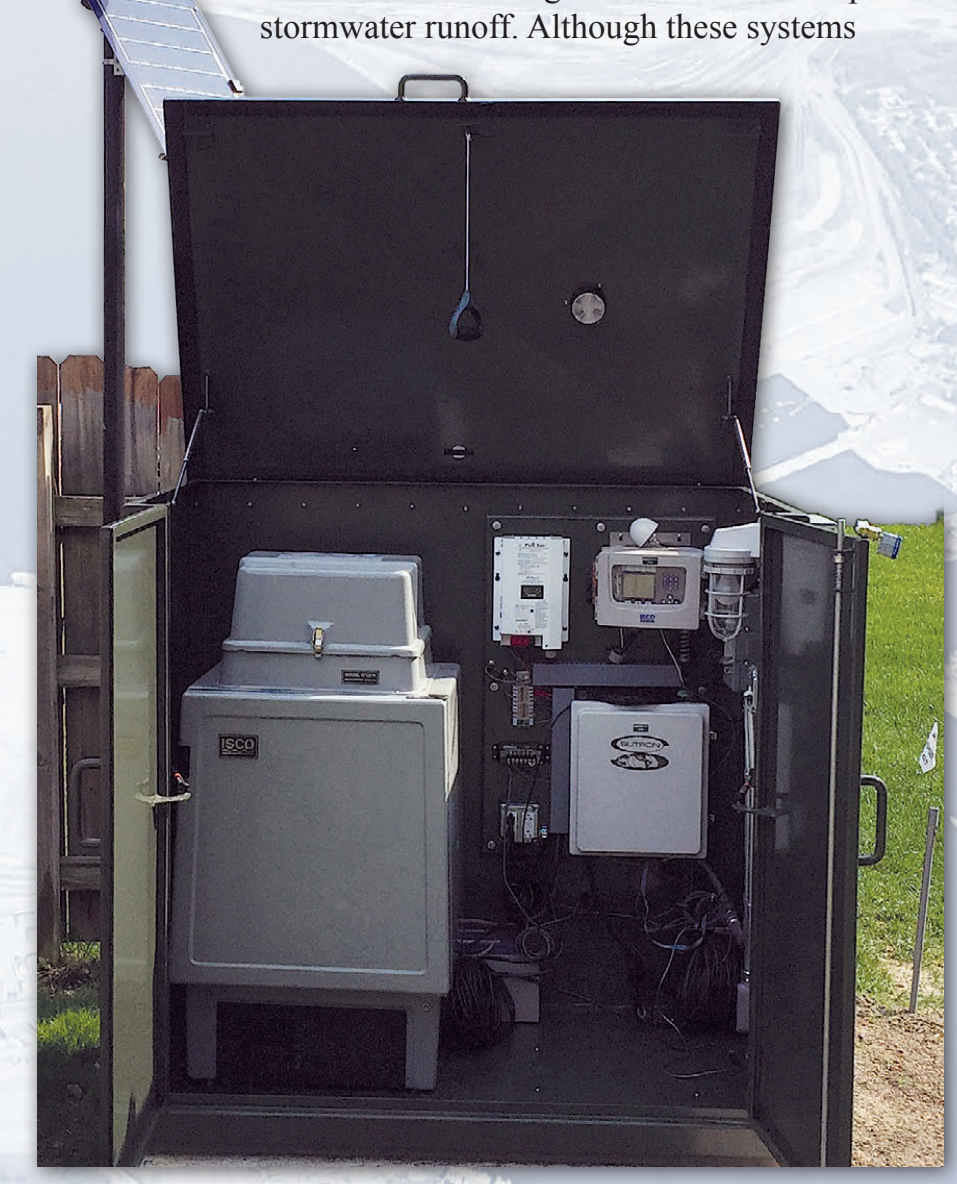

Monitoring station enclosure containing a data logger, telemetry equipment, and refrigerated sampler. 
provide an efficient means to transport stormwater, they also promote rapid transport of contaminants from the landscape to receiving waterbodies. Once in receiving waters, suspended solids can degrade the aquatic environment by reducing both habitat and light availability, which are essential to aquatic organisms. In addition, the overabundance of nutrients in receiving waters can promote excess algal growth that, upon degradation, depletes oxygen required by aquatic life.

\section{How Does the Monitoring Program Work?}

This long-term monitoring program consists of a network of 12 water-quality monitoring stations, 2 per jurisdiction, across the cities of Newport News, Hampton, Portsmouth, Chesapeake, Norfolk, and Virginia Beach. These stations monitor relatively small watersheds, ranging in area from 30 to 300 acres, with a predominant land use in one of three categoriessingle family residential, high density residential, and

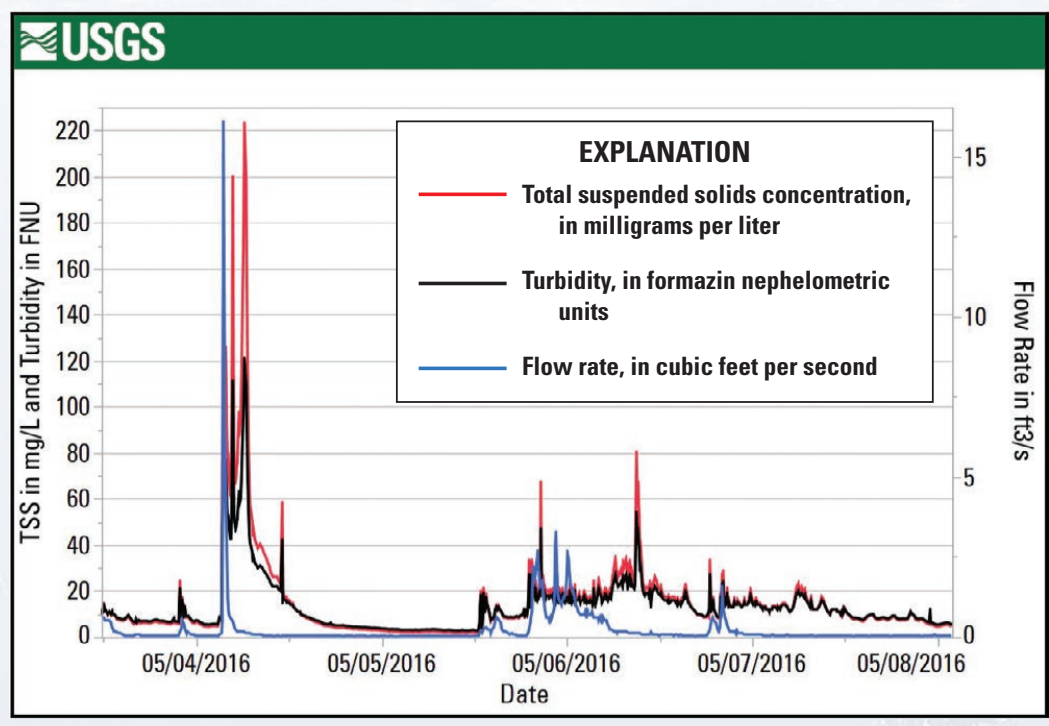

Total suspended solids (TSS) concentrations, in milligrams per liter (mg/L; red); turbidity, in formazin nephelometric units (FNU; black); and flow rate, in cubic feet per second ( $\mathrm{ft} 3 / \mathrm{s}$; blue).

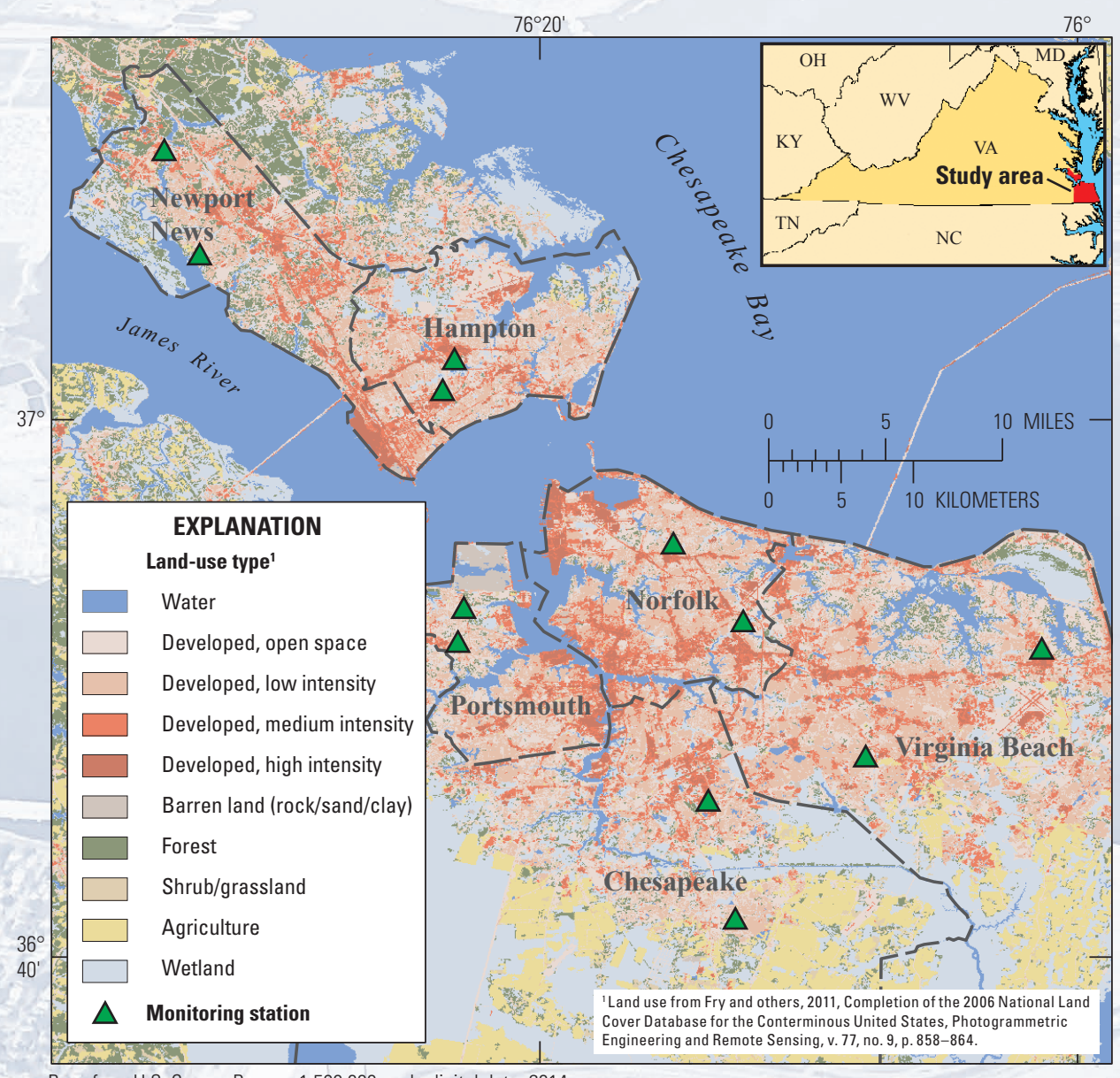

Base from U.S. Census Bureau, 1:500,000-scale digital data, 2014

Network map with monitoring stations and land-use types.

\section{For more information:}

Director, U.S. Geological Survey, Virginia and West Virginia Water Science Center Phone: 804-261-2600 Email: dc_va@usgs.gov

Web: http://va.water.usgs.gov/HRstormwater/ commercial/light industrial. At each station, a data logger, satellite transmitter, and refrigerated automated sampler are housed in a rugged enclosure located alongside or above the stormwater conveyance. These instruments collect data continuously, including flow rate, water temperature, specific conductance, and turbidity; data are automatically uploaded to the USGS online database (http://waterdata.usgs.gov/nwis). Additionally, water samples are collected by the automated sampler during stormflow events and retrieved for analysis of total suspended solids and nutrients by HRSD laboratory staff. Data from these stations are publicly available in near real time (new data posted hourly) via the Hampton Roads Regional Water Quality Program website (http://va.water.usgs. gov/HRstormwater).

The data collected by the waterquality monitoring program will be used to compute monthly and annual nutrient and total suspended solids loads. Ultimately, the program aims to better inform local stormwater management decisions by enhancing understanding of the transport characteristics and loading rates of nutrients and total suspended solids delivered to Chesapeake Bay from these urban landscapes.

\section{- Aaron J. Porter and John D. Jastram}

ISSN 2327-6916 (print) ISSN 2327-6932 (online) https://doi.org/10.3133/fs20163095 